\title{
Season of Birth is Associated with Anthropometric and Neurocognitive Outcomes During Infancy and Childhood in a General Population Birth Cohort
}

\section{Citation}

McGrath, John J., Sukanta Saha, Daniel E. Lieberman, and Stephen Buka. 2006. Season of birth is associated with anthropometric and neurocognitive outcomes during infancy and childhood in a general population birth cohort. Schizophrenia Research 81(1): 91-100.

\section{Published Version}

doi:10.1016/j.schres.2005.07.017

\section{Permanent link}

http://nrs.harvard.edu/urn-3:HUL.InstRepos:3743679

\section{Terms of Use}

This article was downloaded from Harvard University's DASH repository, and is made available under the terms and conditions applicable to Other Posted Material, as set forth at http:// nrs.harvard.edu/urn-3:HUL.InstRepos:dash.current.terms-of-use\#LAA

\section{Share Your Story}

The Harvard community has made this article openly available.

Please share how this access benefits you. Submit a story.

\section{Accessibility}




\title{
Season of birth is associated with anthropometric and neurocognitive outcomes during infancy and childhood in a general population birth cohort
}

\author{
John J. McGrath ${ }^{\mathrm{a}, \mathrm{b}, *}$, Sukanta Saha ${ }^{\mathrm{b}}$, Daniel E. Lieberman ${ }^{\mathrm{c}}$, Stephen Buka ${ }^{\mathrm{d}}$ \\ a Department of Psychiatry, University of Queensland, St Lucia QLD, Australia \\ ${ }^{\mathrm{b}}$ Queensland Centre for Mental Health Research, The Park Centre for Mental Health, Wacol, QLD 4076, Australia \\ ' Department of Anthropology, Harvard University, Peabody Museum, 11 Divinity Avenue, Cambridge MA 02138, USA \\ d Departments of Society, Human Development, and Health and Epidemiology, Harvard School of Public Health, 677 Huntington Avenue, \\ Boston, MA 02115, USA
}

Received 3 June 2005; received in revised form 7 July 2005; accepted 9 July 2005

Available online 20 October 2005

\begin{abstract}
The 'season of birth' effect is one of the most consistently replicated associations in schizophrenia epidemiology. In contrast, the association between season of birth and development in the general population is relatively poorly understood. The aim of this study was to explore the impact of season of birth on various anthropometric and neurocognitive variables from birth to age seven in a large, community-based birth cohort. A sample of white singleton infants born after 37 weeks gestation $(n=22,123)$ was drawn from the US Collaborative Perinatal Project. Anthropometric variables (weight, head circumference, length/height) and various measures of neurocognitive development, were assessed at birth, 8 months, 4 and 7 years of age. Compared to summer/autumn born infants, winter/spring born infants were significantly longer at birth, and at age seven were significantly heavier, taller and had larger head circumference. Winter/spring born infants were achieving significantly higher scores on the Bayley Motor Score at 8 months, the Graham-Ernhart Block Test at age 4, the Wechsler Intelligence Performance and Full Scale scores at age 7, but had significantly lower scores on the Bender-Gestalt Test at age 7 years. Winter/spring birth, while associated with an increased risk of schizophrenia, is generally associated with superior outcomes with respect to physical and cognitive development.
\end{abstract}

(c) 2005 Elsevier B.V. All rights reserved.

Keywords: Seasons; Birth weight; Anthropometry; Human development; Vitamin D

Abbreviations: CPP, Collaborative Perinatal Project; SA, summer-autumn; WISC, Wechsler Intelligence Scale for Children; WS, winterspring.

* Corresponding author. Queensland Centre for Mental Health Research, The Park Centre for Mental Health, Wacol, Q4076, Australia. Tel.: +6173271 8694; fax: +61732718698.

E-mail address: john_mcgrath@qcsr.uq.edu.au (J.J. McGrath). 


\section{Introduction}

There is a sizeable body of literature linking season of birth to psychiatric and neurological disorders (Torrey et al., 1997, 2000). In particular, there is a large body of evidence showing that individuals born in winter and early spring have an approximately $10 \%$ increased risk of later developing schizophrenia (Mortensen et al., 1999; Davies et al., 2003). In light of the consistency of the evidence linking winter/spring birth to schizophrenia, it is important to have a broader understanding of how season of birth impacts on physical growth and cognitive development in the general population.

Compared to summer and autumn babies, those born in winter and spring tend to be heavier (Selvin and Janerich, 1971; Roberts, 1975; Matsuda et al., 1993; Murray et al., 2000; Waldie et al., 2000; Tustin et al., 2004; McGrath et al., 2005, in press) and longer (Wohlfahrt et al., 1998; Waldie et al., 2000; McGrath et al., 2005). These small anthropometric differences persist into adulthood: at age 18 winter/spring born individuals are taller compared to summer/autumn born individuals (Weber et al., 1998; Waldie et al., 2000). The research that has examined season of birth and later cognitive development have produced mixed results (Gordon and Novak, 1950; Berglund, 1967; Farley, 1968; Williams et al., 1970; Kanekar and Mukerjee, 1972; Mascie-Taylor, 1980). With respect to school performance, there is a sizeable body of research showing that summer-born children tend to have poorer educational outcomes (see review by (Martin et al., 2004)). However, it is difficult to partition out the relative contributions of a "true" season of birth effect on neurocognitive development from the fact that summer-born infants in northern hemisphere countries tend to be educationally disadvantaged (due to the interaction between age and school intake policies) (Goodman et al., 2003). A recent US study of children in the fifth grade $(n=7395)$, confirmed that summer-born children did significantly worse on a range of standardized educational tests, and that these seasonal differences persisted when the children outside the appropriate age band (i.e., 'retained' or 'advanced' students) were excluded (Martin et al., 2004).

In summary, the literature based on general population samples suggest that winter/spring born infants tend to (a) be heavier and longer/taller, and (b) have superior educational achievements, compared to summer/autumn born infants. However, if these associations are confirmed in the general population, it raises interesting questions about how to integrate these findings with research focused on schizophrenia. Remembering that the period of the year associated with apparently superior development in the general population (winter/spring) is also associated with an increased risk of schizophrenia (Davies et al., 2003), the literature on the antecedents of schizophrenia shows that children who go on to develop schizophrenia tend to lag behind their peers on a range of physical, neurological, social and educational outcomes (Tarrant and Jones, 1999).

We had the opportunity to explore the association between season of birth and key anthropometric and neurocognitive measures in a large, prospective birth cohort, the US-based Collaborative Perinatal Project. As noted above, the methodological issues in studies exploring the links between season of birth studies and neurocognitive achievements in school age children are substantial. However, longitudinal studies offer one way of addressing these research questions by being able to chart the developmental trajectory prior to and after the onset of schooling. Based on the general population samples summarized above, we predicted that, compared to summer/autumn born group, the winter/spring born group would be heavier, longer/taller, and have larger head circumference at birth, 8 months, 4 and 7 years of age. Based on the literature linking poorer cognitive development in summer born infants, we hypothesized that, compared to summer/autumn born infants, winter/ spring born infants would have higher scores on cognitive measures assessed at 8 months, 4 years and 7 years.

\section{Materials and methods}

\subsection{Subjects}

The Collaborative Perinatal Project (CPP), which involved 12 US sites, enrolled over 50,000 women and their offspring between 1960 and 1967 (Niswander et al., 1975). The offspring of the women were followed-up at regular intervals until age 7 . Detailed 
methods of the overall study, and features related to the physical and cognitive assessments, have been published elsewhere (Broman et al., 1975; Broman et al., 1985).

Studies interested in season of birth effects need to pay close attention to several methodological issues. There is evidence showing that white and black mothers have different seasonal patterns of reproduction (Lam and Miron, 1994). A preliminary analyses of data from the CPP confirmed that while both whites and nonwhites are more likely to be born in summer/ autumn versus winter/spring (overall summer/autumn births $=51.9 \%$ versus winter $/$ spring birth $=48.1 \%$ ), this seasonal variation was significantly larger in nonwhite versus whites $\left(\chi^{2}=6.85, p=0.009\right)$. Because of the known association between ethnicity and birth weight on the one hand (Kramer, 1987) and ethnicity and performance on neurocognitive tests on the other hand (Loehlin, 2000), it was decided to restrict the current analysis to the offspring of white mothers only.

In order to exclude the effects of multiple pregnancies and differential sample attrition, the sample was further restricted to singletons who were alive at age seven. The second important feature of season of birth studies relates to the age-incidence effect. For example, if children born in certain months of the year were more likely to be tested when they were older than children born in the remainder of the year (e.g. follow-up testing for children born near Christmas may be delayed until January), then the cognitive ability of children born in certain months may be differentially affected by this factor. Thus, all post-natal measures were adjusted for age-at-testing. Similarly, because the children's age at school-entry (and thus years of education at the time of testing) can vary as an interaction between season of birth and the academic year (Goodman et al., 2003), we repeated the analyses for cognitive variables at age 7 replacing ageat-testing with duration-of-schooling.

Finally, previous analyses on the full CPP sample revealed seasonality in frequency of preterm birth (defined as less than 36 weeks gestation) (Cooperstock and Wolfe, 1986). In the current analyses, the sample was restricted to those with at least 37 weeks gestation, and in addition, all analyses were corrected for weeks of gestation.

\subsection{Outcome measures}

The main predictor variable in this study is season of birth, while the outcome variables included three anthropometric measures and eight scores derived from five measures of motor and cognitive development. At birth, 8 months, 4 and 7 years of age we examined weight (in grams and kilograms), length or height (in centimetres) and head circumference (in centimetres). At 8 months of age we examined the two scores derived from the Bayley Scales for Infant Development (Bayley, 1969a,b). The Mental Scale assesses aspects of development including sensory discrimination, eye-hand coordination, while the Motor Scale assessed fine and gross motor coordination. At age four the children were given the Stanford Binet Intelligence Scale, Form L-M (Terman and Merrill, 1960; Becker, 2003), and the Graham-Ernhart Block Sort Test, a measure of conceptual and perceptual motor ability that required the children to sort blocks according to various colour, size and shape rules (Graham et al., 1963). At age seven the children were given the Wechsler Intelligence Scale for Children (WISC) in order to derive age-standardized scores for the Performance Score, Verbal Score and the combined Full Scale Score (Wechsler, 1949). Finally, the children at age seven were given the Bender-Gestalt, a test of visual-motor skills that requires the children to copy various figures (Piotrowski, 1995).

\subsection{Analyses}

The main analyses were undertaken with (a) the traditional division of the year into four season (winter=December, January, February; etc), and (b) the year dichotomized as winter/spring (WS; December to May) versus summer/autumn (SA; June to November), in order to focus on the winter/spring period associated with excess schizophrenia births. Using Proc GLM in SAS (SAS Institute, 2001) we modelled the impact of the four level (seasons) and two level (half-year) season of birth variables on the various outcome measure, adjusted for sex, weeks gestation and age-at-testing.

Within this sample we also identified sibships from mothers who had given birth to more than one singleton offspring during the six years of recruitment. 
To reduce the influence of parental and family-related variables that may confound the analyses (e.g. maternal and paternal height, socioeconomic status), we used Proc GENMOD in order to model the relationship between season of birth and the outcomes of interest when examined within sibships, adjusted for sex, weeks gestation and age-at-testing. An additional adjustment for duration of schooling was also made for the psychometric assessments at age 7. For variables that were significantly associated with season of birth in the main analyses, we used (a) Proc SPECTRA ( based on month of birth time series data over the six years of recruitment) in order to look for evidence of circannual periodicity, and (b) plots of overall mean monthly averages in order to inspect the shape of the within-year fluctuation. All $p$ values were two-sided and significance was set at 0.05 .

\section{Results}

There were 11,321 males and 10,802 females included in the main analyses (25 infants with indeterminate or unspe- cified sex were excluded). Slightly more of the infants were born in summer $(26.15 \%)$ compared to the other seasons $(25.05 \%, 24.56 \%, 24.24 \%$ for autumn, spring and winter respectively). This pattern is broadly consistent with the seasonality of births reported in the USA (Lam and Miron, 1994).

Based on the four-season comparisons, there were significant differences for length at birth (highest in winterborn, $p<0.0001$ ), Bayley Motor Score (highest in winterborn, $p<0.0001$ ), Graham-Ernhart Test (highest in springborn, $p=0.04$ ), weight at age 7 (highest in spring-born, $p=0.0003$ ), height at age 7 (highest in spring-born, $p=0.04$ ), head circumference at age 7 (highest in winterborn, $p=0.0001$ ), WISC performance and full scale scores (both highest in spring-born and both $p<0.0001$ ) and Bender Gestalt Test (highest in autumn-born, $p=0.0002$ ). The same pattern of significant findings was found in the half-yearly comparisons. The Table 1 shows the mean unadjusted values for the outcome variables of interest for the half-yearly comparisons WS and SA births. Based on mean values adjusted for sex, weeks gestation and age-at-testing, the difference between SA-WS births is provided with $95 \%$ confidence intervals and $p$ values. Compared to SA births, those born in WS were significantly longer at birth, and were heavier, taller and had larger head circumference at age

Table 1

The comparison between mean summer-autumn versus winter-spring differences in anthropometric and psychometric measure

\begin{tabular}{|c|c|c|c|c|c|c|c|}
\hline \multirow[t]{3}{*}{ Age } & \multirow[t]{3}{*}{ Measurement } & \multicolumn{4}{|l|}{ Singleton analysis } & \multicolumn{2}{|l|}{ Sibship analysis } \\
\hline & & \multirow{2}{*}{$\frac{\text { Summer/autumn }}{n=11,341}$} & \multirow{2}{*}{$\frac{\text { Winter/spring }}{n=10,807}$} & \multirow{2}{*}{$\frac{\text { Difference SAWS }}{(95 \% \mathrm{CI})}$} & \multirow[t]{2}{*}{$p$ value } & \multirow[t]{2}{*}{ SA-WS difference } & \multirow[t]{2}{*}{$p$ value } \\
\hline & & & & & & & \\
\hline \multirow[t]{3}{*}{ Birth } & Weight $^{1}$ & 3335.39 & 3334.66 & $-0.73(-12.95,11.49)$ & 0.91 & -2.62 & 0.82 \\
\hline & Length $^{3}$ & $\mathbf{5 0 . 5 5}$ & 50.63 & $-0.07(-0.14,-0.01)$ & 0.03 & -0.05 & 0.43 \\
\hline & Head circumference ${ }^{3}$ & 34.08 & 34.09 & $-0.01(-0.04,0.03)$ & 0.66 & -0.01 & 0.81 \\
\hline \multirow[t]{5}{*}{8 months } & Weight $^{2}$ & 8.67 & 8.72 & $-0.05(-0.09,0.0004)$ & 0.052 & -0.05 & 0.26 \\
\hline & Length $^{3}$ & 70.00 & 70.10 & $-0.10(-0.24,0.04)$ & 0.15 & -0.11 & 0.46 \\
\hline & Head circumference ${ }^{3}$ & 44.26 & 44.33 & $-0.07(-0.16,0.01)$ & 0.08 & -0.07 & 0.36 \\
\hline & Bayley Mental & 80.10 & 80.18 & $-0.07(-0.21,0.07)$ & 0.33 & -0.11 & 0.38 \\
\hline & Bayley Motor & 33.22 & 34.02 & $-0.80(-0.93,-0.67)$ & $<\mathbf{0 . 0 0 0 1}$ & -0.93 & $<\mathbf{0 . 0 0 0 1}$ \\
\hline \multirow[t]{5}{*}{4 years } & Weight $^{2}$ & 16.68 & 16.76 & $-0.08(-0.21,0.05)$ & 0.24 & 0.04 & 0.73 \\
\hline & Height $^{3}$ & 101.36 & 101.19 & $0.17(-0.63,0.97)$ & 0.68 & -0.24 & 0.39 \\
\hline & Head circumference ${ }^{3}$ & 50.05 & 50.09 & $-0.04(-0.16,0.07)$ & 0.45 & 0.06 & 0.54 \\
\hline & Stanford Binet & 102.47 & 103.35 & $-0.85(-1.75,0.05)$ & 0.06 & -1.02 & 0.17 \\
\hline & Graham-Ernhart & 35.90 & 36.40 & $-0.50(-0.90,-0.10)$ & 0.01 & -0.67 & 0.04 \\
\hline \multirow[t]{7}{*}{7 years } & Weight $^{2}$ & 23.66 & 23.89 & $-0.23(-0.36,-0.11)$ & 0.002 & -0.17 & 0.08 \\
\hline & Height $^{3}$ & 120.51 & 120.71 & $-0.21(-0.36,-0.04)$ & 0.01 & -0.15 & 0.28 \\
\hline & Head circumference ${ }^{3}$ & 51.36 & 51.47 & $-0.11(-0.15,-0.06)$ & $<0.0001$ & -0.10 & 0.006 \\
\hline & WISC-verbal & 50.27 & 50.69 & $-0.42(-0.75,-0.08)$ & 0.01 & 0.08 & 0.77 \\
\hline & WISC performance ${ }^{4}$ & 52.72 & 54.42 & $-1.71(-2.02,-1.59)$ & $<\mathbf{0 . 0 0 0 1}$ & -1.45 & $<\mathbf{0 . 0 0 0 1}$ \\
\hline & WISC full scale ${ }^{4}$ & 103.02 & 105.17 & $-2.15(-2.71,-1.59)$ & $<0.0001$ & -1.38 & 0.003 \\
\hline & Bender-Gestalt ${ }^{4}$ & 5.94 & 5.74 & $0.21(0.11,0.30)$ & $<0.0001$ & 0.16 & 0.06 \\
\hline
\end{tabular}

$1=$ grams, $2=$ kilograms, $3=$ centimetres, $4=$ age-at-testing replaced with duration-of-schooling. SA=summer/autumn; WS=winter/spring. All analyses adjusted for sex, weeks-gestation and age-at-testing. Significant findings are shown in bold. 

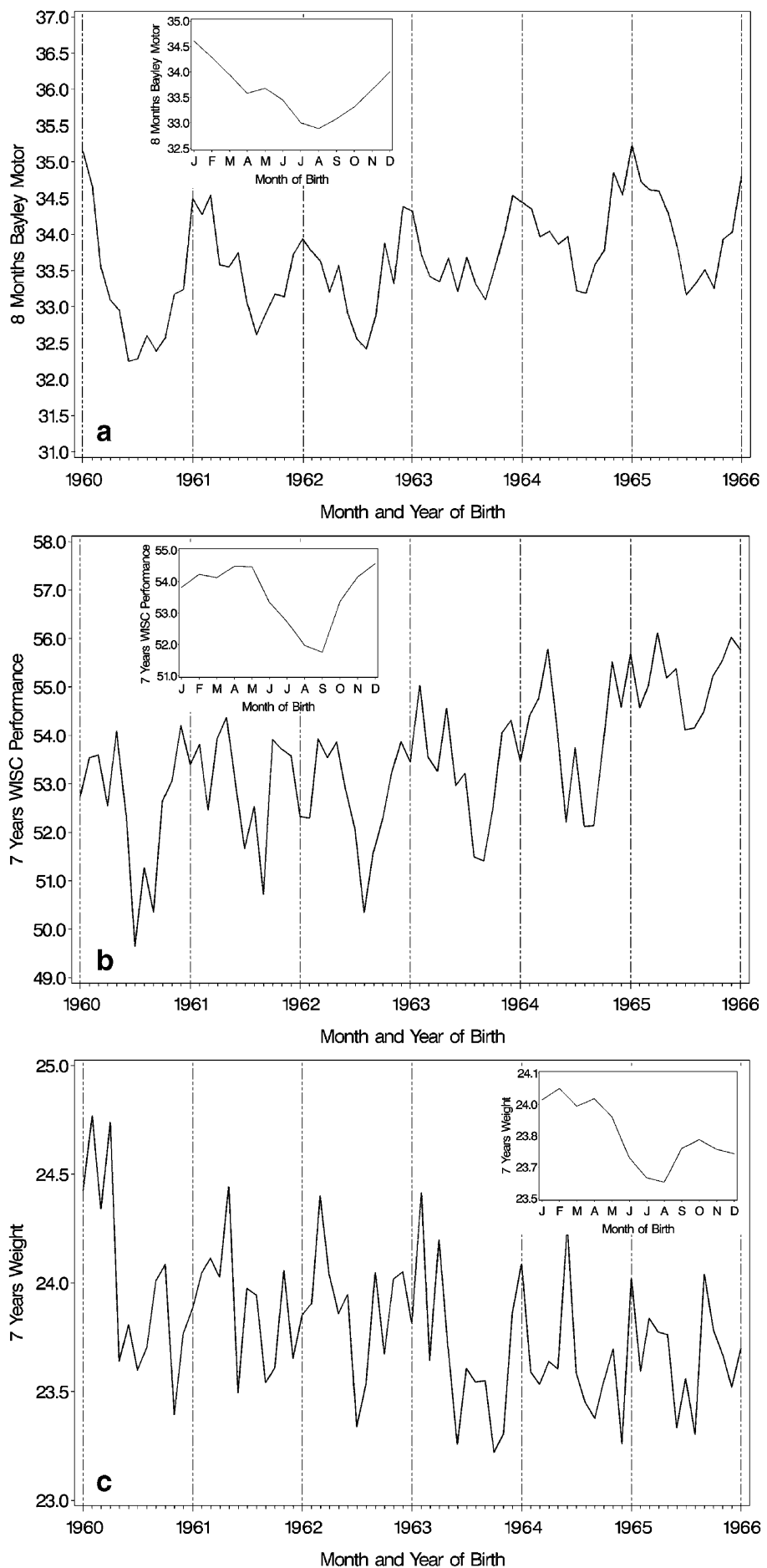

Fig. 1. The upper panel (a) shows the Bayley Motor Score at 8 months, the middle panel (b) shows WISC Performance Score at age 7 years, and the lower panel (c) shows weight at age 7 years. For each panel, the main graph shows the mean monthly values for the time series for births from January 1960 to January 1966 (with a vertical reference line at January). The smaller insert shows the overall mean monthly values. 
7. In addition, compared to the SA born, the WS born infants had superior score on Bayley Motor scales at 8 months, Graham-Ernhart score at 4 years, and the WISC at 7 years. In contrast to all the other findings, the WS born children had significantly lower scores compared to the SA born on the Bender-Gestalt Test at 7 years.

The sibship analyses was based on 7220 singleton offspring of 3262 mothers (2631 mothers had two children, 517 mothers had three offspring, 80 mothers had four offspring, twelve mothers had five offspring and one mother had six offspring). The Table 1 shows the mean difference (adjusted for sex, weeks gestation and age-at-testing; adjusted for duration of schooling for age 7 neurocognitive variables) and $p$ value for each of the outcome variables. Within the sibships, compared to their summer/autumn born siblings, those born in winter/spring had significantly higher scores on the Bayley Motor Scale $(p<0.001)$, the GrahamErnhart Score at 4 years $(p=0.04)$, head circumference at age $7(p=0.006)$, WISC Performance at age $7(p<0.0001)$, WISC Full Scores at age $7(p=0.003)$.

Only five of the nine variables identified as significant in the main analyses showed clear circannual peaks on spectral analysis (weight, height and head circumference at age 7; Bayley Motor Score at 8 monthly; and WISC Performance Score at age 7). By way of example, the raw time series data and the overall mean monthly values for the Bayley Motor Score, weight at age 7 and WISC Performance Score are shown in the Fig. 1.

\section{Discussion}

\subsection{Main findings}

Compared to summer and autumn births, being born in winter and spring was associated with altered physical and neurocognitive outcomes during infancy and childhood. Many of the findings identified in the main sample were also found within a subgroup of sibships, when physical and neurocognitive outcomes of winter/spring born children were compared to their summer/autumn born siblings. Several of the variables had startling circannual periodicity. Overall, the results of the study indicate that prenatal and early life exposures that have regular seasonal fluctuations influence the developmental trajectory in a subtle fashion, at least until age 7 years.

Concerning the anthropometric measures, the associations with season of birth are not found uniformly across the four time points. The lack of a significant seasonal fluctuation in birth weight is congruent with a previous analysis of a subset of the white individuals from the CPP (who overlap with the present subjects) (van Hanswijck de Jonge et al., 2003). However, at birth, winter/spring born babies were significantly longer. The increased length at birth in the winter/ spring born singleton sample is consistent with the Danish (Wohlfahrt et al., 1998) and New Zealand (Waldie et al., 2000) studies. While there were trend-level associations between winter/spring birth and greater weight and head circumference at eight months, season of birth was not significantly associated with any of the anthropometric measure at age eight months nor at four years. In light of the seasonal difference in length at birth, these data suggest that the growth trajectory of children born in different seasons 'caught up' with each other. However the growth trajectories are distinct by age seven. At this assessment, the winter/spring born children were significantly heavier (by 210 grams) and taller (by 0.19 $\mathrm{cm}$ ), and had head circumferences that were significantly larger (by $0.12 \mathrm{~cm}$ ) compared to the summer/ autumn born children. Similar findings emerged when the analyses were repeated on derived indices of weight and height such as ponderal index and body mass index (data not shown).

As with the anthropometric measures, season of birth was not associated with all neurocognitive measures at follow-up. There was a striking association between winter/spring birth and improved performance on the Motor component of the Bayley's Scale for infant development (but not with the Bayley Mental Score). These findings are consistent with two previous studies that found winter/spring born babies achieved motor milestones earlier than summer/ autumn born babies (Hayashi, 1990; Benson, 1993). At age 4, the winter/spring born children were do better on block sorting and there was a trend level $(p=0.06)$ association with superior Stanford-Binet scores. By age 7, the winter/spring born children were scoring better on the performance subscore of the WISC (but not the Verbal subscore). While the winter/spring born children were scoring over 2 units higher on the WISC Full Scale, they were also significantly worse on the Bender Gestalt Test (a measure of visuo-constructive ability). The evolving pattern of findings over time suggests that the seasonally-fluctuating exposure that influences brain devel- 
opment differentially influences some domains (e.g. fine and gross motor coordination) more so than others (e.g. sensory discrimination ability).

The overall pattern of findings (i.e. that winter/ spring babies are both 'bigger' on the anthropometric variables and 'smarter' on the selected neurocognitive variables) is consistent with the general literature linking birth weight and cognitive development. For example, within the normal range of birth weight, various cohort studies have found that heavier neonates have superior cognitive ability at age 7 years (Matte et al., 2001; Jefferis et al., 2002), 8 years (Richards et al., 2001) 11 years (Shenkin et al., 2001) and 18 years (Sorensen et al., 1997). In addition, many studies have identified a positive correlation between head circumference (or brain volume) and cognitive ability (see review (Vernon et al., 2000)).

However, the findings raise interesting questions about how to reconcile these findings with the link between winter/spring birth and risk of schizophrenia. The evidence from prospective cohort studies has shown that children who go on to develop schizophrenia tend to have delayed motor and cognitive trajectories (Tarrant and Jones, 1999), and generally have low birth weight and smaller head circumference at birth (Cannon et al., 2002). A population-based cohort study from Helsinki reported that the children who went on to develop schizophrenia were "thinner" (i.e. lower weight but normal height) at age 7 and 15 years (Wahlbeck et al., 2001). Studies based on highrisk children (i.e. the offspring of women with schizophrenia) suggest that a more complex pattern of 'catch-up' growth (e.g. smaller at birth, but heavier as children) may be associated with risk of later schizophrenia (Niemi et al., 2005).

Some clues into this paradox can be found in a separate analysis of a subsample of the Collaborative Perinatal Project. Based on a subgroup of cohort members born at one site of the CPP (Providence, R.I.; $n=547$ ), a significant association was found between a decline in general intellectual ability between ages 4 and 7 and an increased risk of adult psychotic symptoms (as assessed at age 23) (Kremen et al., 1998). The risk of psychotic symptoms was not associated with the actual level of intelligence at the two time points, but was linked to those that had a decline over this time. These finding suggest that the trajectory of neurocognitive development is altered in psychosis, in keeping with modern revisions of the neurodevelopmental hypothesis that place emphasis on the progressive nature of the dysfunction (DeLisi, 1997; McGrath et al., 2003). We speculate that the 'season of birth effect' may subtlety shift the trajectory of growth for the entire population (e.g. winter/ spring associated with superior outcomes), however other factors (e.g. underlying genetic susceptibilities, other environmental exposures) may be required in order to compromise the trajectory, which then leads to the development patterns associated with schizophrenia. However, it should be noted that data on the full CPP cohort were only available until age seven. It is feasible that any early developmental 'credits' associated with winter/spring birth could be off-set with later 'deficits' that do not become apparent until after age seven. In other words, perhaps winter/spring birth results in both; (a) a slightly steeper trajectory of general development during early life and (b) a slightly steeper trajectory of involution during adolescents and adulthood. These notions of trade-offs within a finite 'growth budget' warrant examination in other datasets.

\subsection{Interpretation of findings}

Clearly, anthropometric and neurocognitive variables from birth to age seven are influenced by a complex matrix of genetic and epigenetic factors operating on the maternal-fetal unit and on the developing individual. While this study does not allow us to tease apart causality, the most parsimonious interpretation is that one exposure (or one set of exposures) that fluctuate across seasons underlies the pattern of both anthropometric and neurocognitive outcomes identified in this study. In other words, both the physical and cognitive findings are downstream expressions of the same primary biological perturbation associated with season of birth.

There are many candidate exposures that have regular, seasonal fluctuations. Ultimately, most of candidate exposures are down-stream consequences of biometeorological variables such as temperature, rainfall and ultraviolet radiation. These variables (cold, heat stress, dehydration) can impact directly on health status (McGeehin and Mirabelli, 2001; Naughton et al., 2002; Mercer, 2003). Winter is asso- 
ciated with lower levels of ultraviolet radiation, which is strongly associated with low levels of vitamin D (Holick, 1995). Indirectly, seasonal fluctuations can impact on health status via nutrition (e.g. availability of seasonal food products like fruit), energy expenditure (e.g. work load varies across seasons in agrarian societies), and disease exposures (e.g. respiratory viruses may be more prevalent in winter, vectors for malaria have seasonal breeding cycles) (McMichael, 2001). In addition to this complex web of environmental changes, human behaviour is modified in a transactional fashion with the environment. For example, in cold seasons, we tend to remain indoors, use internal heating and wear more clothing. Thus, seasonal changes in weather can result in a complex but highly inter-correlated matrix of exposures.

Murray and colleagues have argued that exposure to cold temperatures during mid-gestation can reduce placental blood flow, and thus lead to lower birth weights associated with late spring and in summer (Murray et al., 2000). Prenatal infection also warrants further research, in particular viruses that fluctuation with seasons (e.g. respiratory viruses that are more prevalent in winter), as these can impact on fetal development (Griffiths et al., 1980; Torrey et al., 2000).

Vitamin D has clear seasonal fluctuations, with hypovitaminosis D becoming more prevalence at the end of winter and early spring (Holick, 1995). Vitamin D has been shown to induce the transcription of a large number of target genes (Darwish and DeLuca, 1993) and can modulate development via interactions with known morphogens such as retinoic acid and thyroid hormone. The presence of vitamin D dampens proliferation, and induces cells to exit the cell cycle via differentiation and, in certain circumstances, induces apoptosis (DeLuca et al., 1990). Hypovitaminosis D (in the presence of normal calcium) in the pregnant guinea pig has been found to cause widened growth plates in the fetal long bones (Rummens et al., 2002), thus this feature may underlie the longer length of winter-spring born infants (McGrath et al., 2005). The altered cognitive trajectory noted in this study may be as a consequence of the impact of low prenatal vitamin D on brain development. Recent animal experiments have shown that transient prenatal hypovitaminosis D were associated with changes in neonatal and adult rat brain morphol- ogy (e.g. increased lateral ventricle volume), as well as reduced Nerve Growth Factor and Glial Derived Neurotrophin Factor (Eyles et al., 2003; Feron et al., 2005). The findings from animal experiments are consistent with recent evidence from observational studies of the offspring of mothers with low vitamin D. Compared to newborn infants with normal vitamin $\mathrm{D}$, those with low vitamin $\mathrm{D}$ were significantly heavier and longer, and had larger head circumference (Weiler et al., 2005).

Finally, the mismatch between the general population findings concerning season of birth effects on cognitive and physical development versus the season of birth effects on risk of schizophrenia, suggest that more complex solutions need to be found. Perhaps there are subtle interactions between the timing and duration of the exposure during different critical windows of prenatal and early life development that result in different developmental pathways. For example, it is feasible that if the second trimester falls in winter or spring, then low vitamin D restricted to this critical period of growth (i.e. normal vitamin $\mathrm{D}$ during the first and third trimesters) could underlie the adverse outcomes associated with summer and autumn birth. Perhaps low vitamin D during the third trimester only (or second and third trimester combined) result in different outcomes with respect to growth and to risk for schizophrenia. Large, population-based birth cohorts with maternal sera from several time points as well as samples from the neonate will be needed to resolve issues such as these.

The fact that season of birth impacts on the developmental trajectories of a general population birth cohort underlines the importance of generating candidate exposures for further analytic epidemiological studies. While most of the seasons of birth differences were small at the individual level, these could have important implications from a public health perspective (Rose, 1992). If these environmental factors can be identified, it may be possible to develop preventive interventions (universal or selective) that could optimize neurocognitive development regardless of season-of-birth. If we are ever to unravel the mechanisms that link winter/spring birth to an increased risk of schizophrenia, perhaps our best strategy is to first consider the wider implications of how winter/spring birth impacts on growth and development in the general population. 


\section{Acknowledgements}

JM was supported by a Queensland-Smithsonian Institution Fellowship. JM and SB are supported by the Stanley Medical Research Institute.

\section{References}

Bayley, N., 1969a. Bayley Scales of Infant Development. Psychological Corporation, San Antonio, TX.

Bayley, N., 1969b. Manual for the Bayley Scales of Infant Development. The Psychological Corporation, New York.

Becker, K.A., 2003. History of the Stanford-Binet intelligence scales: content and psychometrics. Stanford-Binet Intelligence Scales, (Fifth edition). Assessment Service Bulletin, vol. 1. Riverside Publishing, Itasca, IL.

Benson, J.B., 1993. Season of birth and onset of locomotion: theoretical and methodological implications. Infant Behav. Dev. 16, 69-81.

Berglund, G.W., 1967. A note on intelligence and season of birth. Br. J. Psychol. 58, 147-151.

Broman, S.H., Nichols, P.L., Kennedy, W.A., 1975. Preschool IQ. Prenatal and Early Developmental Correlates. Lawrence Erlbaum Associates, Hillsdale, New Jersey.

Broman, S., Bien, E., Shaughnessy, P., 1985. Low Achieving Children: the First Seven Years. Lawrence Erlbaum Associates, Hillsdale, New Jersey.

Cannon, M., Jones, P.B., Murray, R.M., 2002. Obstetric complications and schizophrenia: historical and meta-analytic review. Am. J. Psychiatr. 159, 1080-1092.

Cooperstock, M., Wolfe, R.A., 1986. Seasonality of preterm birth in the collaborative perinatal project: demographic factors. Am. J. Epidemiol. 124, 234-241.

Darwish, H., DeLuca, H.F., 1993. Vitamin D-regulated gene expression. Crit. Rev. Eukaryot Gene Expr. 3, 89-116.

Davies, G., Welham, J., Chant, D.C., Torrey, E.F., McGrath, J., 2003. Season of birth effect and latitude: a systematic review and meta-analysis of northern hemisphere studies. Schizophr. Bull. 29, 587-593.

DeLisi, L.E., 1997. Is schizophrenia a lifetime disorder of brain plasticity, growth and aging? Schizophr. Res. 23, 119-129.

DeLuca, H.F., Krisinger, J., Darwish, H., 1990. The vitamin D system: 1990. Kidney Inter., Suppl. 29, S2-S8.

Eyles, D., Brown, J., Mackay-Sim, A., McGrath, J., Feron, F., 2003. Vitamin D3 and brain development. Neuroscience 118, $641-653$.

Farley, F.H., 1968. Season of birth, intelligence and personality. Br. J. Psychol. 59, 281-283.

Feron, F., Burne, T.H., Brown, J., Smith, E., McGrath, J.J., MackaySim, A., Eyles, D.W., 2005. Developmental vitamin D3 deficiency alters the adult rat brain. Brain Res. Bull. 65, 141-148.

Goodman, R., Gledhill, J., Ford, T., 2003. Child psychiatric disorder and relative age within school year: cross sectional survey of large population sample. BMJ 327, 472.
Gordon, H.C., Novak, B.J., 1950. I.Q. and month of birth. Science $112,62-63$.

Graham, F.K., Ernhart, C.B., Berman, P.W., 1963. Brain Injury in the Preschool Child: Some Developmental Considerations! Performance of Normal Children. .

Griffiths, P.D., Ronalds, C.J., Heath, R.B., 1980. A prospective study of influenza infections during pregnancy. J. Epidemiol. Community Health 34, 124-128.

Hayashi, K., 1990. Correlation between temperature and infants' gross motor development. Dev. Med. Child Neurol. $32,833-834$.

Holick, M.F., 1995. Environmental factors that influence the cutaneous production of vitamin D. Am. J. Clin. Nutr. 61, $638 \mathrm{~S}-645 \mathrm{~S}$.

Jefferis, B.J., Power, C., Hertzman, C., 2002. Birth weight, childhood socioeconomic environment, and cognitive development in the 1958 British Birth Cohort Study. BMJ 325, 305.

Kanekar, S., Mukerjee, S., 1972. Intelligence, extraversion, and neuroticism in relation to season of birth. J. Soc. Psychol. 86, 309-310.

Kramer, M.S., 1987. Determinants of low birth weight: methodological assessment and meta-analysis. Bull. World Health Organ., Suppl. 65, 663-737.

Kremen, W.S., Buka, S.L., Seidman, L.J., Goldstein, J.M., Koren, D., Tsuang, M.T., 1998. IQ decline during childhood and adult psychotic symptoms in a community sample: a 19-year longitudinal study. Am. J. Psychiatr. 155, 672-677.

Lam, D.A., Miron, J.A., 1994. Global patterns of seasonal variation in human fertility. Ann. N. Y. Acad. Sci. 709, 9-28.

Loehlin, J.C., 2000. Group differences in intelligence. In: Sternberg, R.J. (Ed.), Handbook of Intelligence. Cambridge University Press, Cambridge, pp. 176-193.

Martin, R.P., Foels, P., Clanton, G., Moon, K., 2004. Season of birth is related to child retention rates, achievement, and rate of diagnosis of specific LD. J. Learn. Disabil. 37, 307-317.

Mascie-Taylor, C.G.N., 1980. Season of birth, IQ components and personality traits. J. Genet. Psychol. 137, 151-152.

Matsuda, S., Sone, T., Doi, T., Kahyo, H., 1993. Seasonality of mean birth weight and mean gestational period in Japan. Hum. Biol. 65, 481-501.

Matte, T.D., Bresnahan, M., Begg, M.D., Susser, E., 2001. Influence of variation in birth weight within normal range and within sibships on IQ at age 7 years: cohort study. BMJ 323, 310-314.

McGeehin, M.A., Mirabelli, M., 2001. The potential impacts of climate variability and change on temperature-related morbidity and mortality in the United States. Environ. Health Perspect. 109 (Suppl 2), 185-189.

McGrath, J., Feron, F., Burne, T.H.J., Mackay-Sim, A., Eyles, D., 2003. The neurodevelopmental hypothesis of schizophrenia; a review of recent developments. Ann. Med. 35, 86-93.

McGrath, J.J., Keeping, D., Saha, S., Chant, D.C., Lieberman, D.E., O'Callaghan, M.J., 2005. Seasonal fluctuations in birth weight and neonatal limb length; does prenatal vitamin D influence neonatal size and shape? Early Hum. Dev. 81 (7), 609-618.

McGrath, J., Barnett, A.G., Eyles, D., in press. The association between birth weight, season of birth and latitude. Annals of Human Biology. 
McMichael, A.J., 2001. Human Frontiers, Environments and Disease. Cambridge University Press, Cambridge.

Mercer, J.B., 2003. Cold - an underrated risk factor for health. Environ. Res. 92, 8-13.

Mortensen, P.B., Pedersen, C.B., Westergaard, T., Wohlfahrt, J., Ewald, H., Mors, O., Andersen, P.K., Melbye, M., 1999. Effects of family history and place and season of birth on the risk of schizophrenia. New Engl. J. Med. 340, 603-608.

Murray, L.J., O'Reilly, D.P., Betts, N., Patterson, C.C., Davey Smith, G., Evans, A.E., 2000. Season and outdoor ambient temperature: effects on birth weight. Obstet. Gynecol. 96, $689-695$.

Naughton, M.P., Henderson, A., Mirabelli, M.C., Kaiser, R., Wilhelm, J.L., Kieszak, S.M., Rubin, C.H., McGeehin, M.A., 2002. Heat-related mortality during a 1999 heat wave in Chicago. Am. J. Prev. Med. 22, 221-227.

Niemi, L.T., Suvisaari, J.M., Haukka, J.K., Lonnqvist, J.K., 2005. Childhood growth and future development of psychotic disorder among Helsinki high-risk children. Schizophr. Res. 76, $105-112$.

Niswander, K.R., Gordon, M., Drage, J.S., 1975. Effect of intrauterine hypoxia on child surviving to 4 years. Am. J. Obstet. Gynecol. 121, 892-899.

Piotrowski, C., 1995. A review of the clinical and research use of the Bender-Gestalt Test. Percept. Mot. Skills 81, 1272-1274.

Richards, M., Hardy, R., Kuh, D., Wadsworth, M.E., 2001. Birth weight and cognitive function in the British 1946 Birth Cohort: longitudinal population based study. BMJ 322, 199-203.

Roberts, D.F., 1975. Environment and the fetus. In: Roberts, D.F., Thomson, A.M. (Eds.), The Biology of Human Fetal Growth. Taylor and Francis, London.

Rose, G., 1992. The Strategy of Preventive Medicine. Oxford University Press, Oxford.

Rummens, K., van Bree, R., Van Herck, E., Zaman, Z., Bouillon, R., Van Assche, F.A., Verhaeghe, J., 2002. Vitamin D deficiency in guinea pigs: exacerbation of bone phenotype during pregnancy and disturbed fetal mineralization, with recovery by 1,25(OH)2D3 infusion or dietary calcium-phosphate supplementation. Calcif. Tissue Int. 71, 364-375.

SAS Institute, 2001. SAS, vol. 8.02. Cary, NC.

Selvin, S., Janerich, D.T., 1971. Four factors influencing birth weight. Br. J. Prev. Soc. Med. 25, $12-16$.

Shenkin, S.D., Starr, J.M., Pattie, A., Rush, M.A., Whalley, L.J., Deary, I.J., 2001. Birth weight and cognitive function at age 11 years: the Scottish mental survey 1932. Arch. Dis. Child. 85, $189-196$.
Sorensen, H.T., Sabroe, S., Olsen, J., Rothman, K.J., Gillman, M.W., Fischer, P., 1997. Birth weight and cognitive function in young adult life: historical cohort study. BMJ 315, 401-403.

Tarrant, C.J., Jones, P.B., 1999. Precursors to schizophrenia: do biological markers have specificity? Can. J. Psychiatry 44, $335-349$.

Terman, L.M., Merrill, M.A., 1960. Stanford-Binet Intelligence Scale. Houghton Mifflin, Boston.

Torrey, E.F., Miller, J., Rawlings, R., Yolken, R.H., 1997. Seasonality of births in schizophrenia and bipolar disorder: a review of the literature. Schizophr. Res. 28, 1-38.

Torrey, E.F., Miller, J., Rawlings, R., Yolken, R.H., 2000. Seasonal birth patterns of neurological disorders. Neuroepidemiology 19, $177-185$.

Tustin, K., Gross, J., Hayne, H., 2004. Maternal exposure to firsttrimester sunshine is associated with increased birth weight in human infants. Dev. Psychobiol. 45, 221-230.

van Hanswijck de Jonge, L., Waller, G., Stettler, N., 2003. Ethnicity modifies seasonal variations in birth weight and weight gain of infants. J. Nutr. 133, 1415-1418.

Vernon, P.A., Wickett, J.C., Bazana, G., Stelmack, R.M., 2000. The neuropsychology and psychophysiology of human intelligence. In: Sternberg, R.J. (Ed.), Handbook of Intelligence. Cambridge University Press, Cambridge, pp. 245-264.

Wahlbeck, K., Forsen, T., Osmond, C., Barker, D.J., Eriksson, J.G., 2001. Association of schizophrenia with low maternal body mass index, small size at birth, and thinness during childhood. Arch. Gen. Psychiatry 58, 48-52.

Waldie, K.E., Poulton, R., Kirk, I.J., Silva, P.A., 2000. The effects of pre- and post-natal sunlight exposure on human growth: evidence from the southern hemisphere. Early Hum. Dev. 60, $35-42$.

Weber, G.W., Prossinger, H., Seidler, H., 1998. Height depends on month of birth. Nature 391, 754-755.

Wechsler, D., 1949. Manual for the Wechsler Intelligence Scale for Children. Psychological Corp, New York.

Weiler, H., Fitzpatrick-Wong, S., Veitch, R., Kovacs, H., Schellenberg, J., McCloy, U., Yuen, C.K., 2005. Vitamin D deficiency and whole-body and femur bone mass relative to weight in healthy newborns. CMAJ, Can. Med. Assoc. J. 172, 757-761.

Williams, P., Davies, P., Evans, R., Ferguson, N., 1970. Season of birth and cognitive development. Nature 228, 1033-1036.

Wohlfahrt, J., Melbye, M., Christens, P., Andersen, A.M., Hjalgrim, H., 1998. Secular and seasonal variation of length and weight at birth. Lancet 352, 1990. 